\title{
Las percepciones de la actual política exterior Argentina sobre la política exterior del Brasil y las relaciones Estados Unidos - Brasil.
}

\author{
Dr. Raúl Bernal-Meza.
}

El presente artículo entrega elementos para el análisis, a partir de las interpretaciones dominantes en la formulación de la actual política externa argentina acerca del Brasil, Estados Unidos y las agendas política, de seguridad $y$ de comercio (Mercosur; $A L C A$ ).

El presente documento constituye un aporte a la identificación de las dificultades que han surgido, durante los años 1990, en las relaciones entre Argentina y Brasil, las que tienen su origen en las distintas concepciones e interpretaciones sobre el "nuevo orden emergente" y el sistema internacional, sobre la inserción internacional del paîs y su posición en el mundo, así como en las distintas y complejas características de ambos países, en lo social, lo económico y lo cultural.

\section{Advertencia metodológica}

Siendo nuestra preocupación la identificación de las percepciones argentinas sobre la política exterior del Brasil y sobre las relaciones BrasilEstados Unidos, que incluyen tanto los aspectos políticos y de seguridad, como aquellos referidos a los proyectos en cursos sobre integración subregional (Mercosur), regional (ALCSA) y hemisféricos (NAFTAALCA), la selección del índice temático sigue ese objetivo, remitiendo a otros estudios los análisis comparativos de naturaleza más abarcativa.

Para la recolección de información se utilizaron fundamentalmente fuentes primarias (entrevistas con especialistas vinculados a los grupos con acceso a la formulación de la política exterior argentina actual, académicos y miembros del cuerpo diplomático), como secundarias (publicaciones específicas, artículos y libros recientes). 


\section{Introducción: los antecedentes (1940-1960)}

Como han señalado diversos autores (Tomassini, 1980; van Klaveren, 1984; Russell,1992), los estudios internacionales en América Latina fueron una preocupación de grupos muy reducidos, centrados en torno a institutos y escuelas militares, los Servicios Exteriores y un núcleo muy pequeño más académico. En el caso de Argentina, la producción, hasta fechas recientes, ha tendido a ser más interpretativa y explicativa que descriptiva (Colacrai,1992).

Hasta 1960 los temas y enfoques analíticos dominantes corresponden a la línea "histórico-jurídica" de las relaciones internacionales, como también es el caso en Chile, las que siguen los ejes propios de la historia diplomática. El período 1940-1960 es una etapa de creación de doctrinas nacionales, como la "Doctrina Drago" y la "Tercera Posición"1, con relevancia del enfoque histórico y prescripciones de política de tipo idealista y realismo-pragmatismo.

Sin embargo, en el abordaje de los problemas limítrofes y del espacio (terrestre, aéreo, marítimo), la literatura ha sido predominantemente de perspectiva geopolítica, muy vinculada a la estrategia nacional (Colacrai,1992:23). Es en esa línea que se inscribe la lectura sobre la política exterior brasileña ${ }^{2}$.

En la consolidación de este pensamiento geopolítico, ligado a la elaboración de un proyecto nacional, que se asocia a la búsqueda de la autonomía, la integración surge como un instrumento útil. Pero aquí también aparecen matices, según el énfasis puesto en la rivalidad argentino-brasileña. Según Colacrai, estos matices podrían resumirse en dos:

a) La visión de Brasil como "gendarme armado" de América del Sur" y satélite privilegiado de Estados Unidos (Gualco,1972).

\footnotetext{
'Ver, Raúl Bernal-Meza, América Latina en la Economía Política Mundial, Buenos Aires, Grupo Editor Latinoamericano, 1994; Segunda Parte.

'Entre los autores que han hecho referencia estos aspectos, cfr. CONIL PAZ, Alberto y FERRARI, Gustavo, Política Exterior Argentina 1930-1960, Buenos Aires, Huemul, 1964; RUIZ MORENO, Isidoro, Historia de las relaciones exteriores argentinas 1810-1955, Buenos Aires, A. Perrot, 1958; ETCHEPAREBORDA, Roberto, "La política externa argentina 1870-1920", en Anuario de Historia, Córdoba, 1967. PUIG, Juan Carlos, "La Política Exterior Argentina: incongruencia epidérmica y coherencia estructural", en PUIG, Juan Carlos (Comp.), América Latina: Políticas Exteriores Comparadas, Buenos Aires, Grupo Editor Latinoamericano, 1984; Tomo 1, pp. 91-169.
} 
b) Otra visión que reconoce las divergencias con Brasil, pero que considera posible la concertación de acciones bilaterales, evitando las confrontaciones en el Cono Sur (Guglialmelli,1975).

En el período 1976-1983 se produce un distanciamiento significativo respecto de objetivos como "integración" y "autonomía" (o liberación), pasando a ser predominantes los enfoques sobre Doctrina de la Seguridad Nacional, las políticas de poder y la geopolítica de fronteras.

La combinación de geopolítica y política de poder se hace más evidente y casi excluyente en los estudios vinculados a la política exterior argentina, con recurrencia a las percepciones sobre rivalidad, competencia y conflicto. Se trata de una corriente geopolítica de confrontación, circunscrita al área de los vecinos: Brasil y Chile (Colacrai,1992:25-6). Otros elementos del realismo surgen asimismo al abordar temas vinculados a la revisión del papel de Argentina en el sistema de poder regional, que en relación al Brasil vuelven a remitir a la necesidad de mantener con éste un "equilibrio de poder".

Desde la perspectiva histórica, los approches teóricos, interpretativos o normativos, aplicados al estudio de las relaciones con Brasil, marcan una predominancia de las percepciones de conflicto. La relación histórica, hasta 1980, estuvo sesgada por una preocupación esencialmente política (o geopolítica), no por una relación económica y comercial, que fue, en todo caso, marginal. Como han señalado también autores brasileños, en la dimensión político-estratégica, ambos países mantuvieron, durante décadas y por extensos períodos históricos una rivalidad por el predominio sobre la Cuenca del Plata, compitiendo por el liderazgo político en la región (Bandeira,1995). Históricamente las respectivas cancillerías definieron las políticas bilaterales a partir de criterios geopolíticos y de teorías de equilibrio de poder y balance militar en América del Sur (de la Balze,1995:77). No obstante, también las estrategias de desarrollo, "primario-exportador" antes, de "desarrollo hacia adentro y sustitutivo de importaciones" después, contribuyeron al distanciamiento o, al menos al desinterés bilateral.

En conclusión, en el período 1960-1983, los aspectos conflictivos de las relaciones con Brasil tienen una gran relevancia. Las argumentaciones, basadas en la recurrencia a una historia de conflictos por la hegemonía subregional que se remontan al período del Imperio del Brasil, se fortalecen 
ahora con la lectura comparativa de las diferencias en el desarrollo económico entre ambos países. El "milagro brasileño", frente al estancamiento relativo de la Argentina conducen los enfoques desde el concepto predominante de la rivalidad tradicional a otro que pone de relevancia la hegemonía brasileña en la región (Bernal-Meza,1989;Colacrai,1992). Autores como Sanz (1976) ven a Brasil tras un proyecto de hegemonía y dominación sobre el Cono Sur.

En general esta interpretación se basa en la lectura de los propios teóricos y analistas brasileños identificados con la línea geopolítica, como Golbery do Couto e Silva y Travassos.

Los elementos comparativos que fortalecen las percepciones de riesgo para la Argentina se relacionan con:

a) el importante desarrollo industrial brasileño y su relación con la provisión de material a sus fuerzas armadas.

b) la concentración demográfica en los Estados del sur brasileño.

c) las relaciones bilaterales y la influencia sobre Estados vecinos que comparten la cuenca amazónica (Bolivia, Paraguay).

d) el conflicto por la utilización de los recursos hídricos y la construcción de represas hidroeléctricas en el Alto Paraná.

e) la expansión de los intereses brasileños a la Antártida.

La predominancia de los enfoques geopolíticos, en el período 19701983 contribuyó a que la mayor parte de los trabajos sobre política exterior argentina tuvieran como común denominador la geopolítica-política de poder (Colacrai,1992:47). Esta producción influyó tanto sobre los "formuladores de política" como sobre la sociedad, proceso en el cual tuvieron particular incidencia sectores "formadores de opinión" (periodistas, intelectuales). El resultado del empleo de categorías de naturaleza explicativa mono causal fue el fomento de percepciones de confrontación y conflicto (Bernal-Meza,1989).

El "milagro brasileño" tuvo como expresión de política exterior, desde la perspectiva argentina, la visualización de las relaciones entre Brasil y Estados Unidos como las de una amistad entre iguales, que se expresaba en el concepto Brasil potencia emergente o Brasil potencia regional, 1o que claramente constituía un peligro para las percepciones de Argentina respecto de su propio papel en la política sudamericana y hemisférica. 


\section{El cambio de percepción: 1983-1998}

Si bien se reconoce que la transición en las relaciones bilaterales y en las percepciones argentinas sobre la política exterior brasileña tienen dos antecedentes importantes (el Acuerdo Tripartito de aprovechamiento de los recursos hídricos y sobre las cotas de altura, y el acercamiento sobre cooperación nuclear), el retorno a un gobierno democrático en Argentina surge como el elemento estructural para el cambio de la visión sobre el Brasil y las relaciones argentino-brasileñas.

Aunque la variable tipo de régimen aparece como un aspecto fundamental para el cambio de percepciones, influyendo en la evolución del pensamiento geopolítico, distintos factores inciden es este cambio; entre ellos:

a) la guerra de las Malvinas y la posición que adoptan los países latinoamericanos en apoyo de la Argentina, hechos que pusieron de relevancia nuevamente, en el imaginario político argentino, los "principios solidarios de la integración latinoamericana".

b) la solución del conflicto con Chile sobre el Beagle (1984), que evidenciaba la factibilidad de llegar a acuerdos sobre temas muy difíciles, aún con gobiernos militares.

c) el valor del proceso de democratización en América del Sur, que realza la necesidad de impulsar la cooperación política para el restablecimiento integral de la democracia y para el desarrollo.

d) la llegada al gobierno de formuladores de política y asesores, que ponen mayor énfasis en las relaciones cooperativas que en las conflictivas.

e) la firma de los acuerdos de integración con Brasil (1986).

f) el progreso alcanzado en los estudios internacionales desde mediados de los años de 1980, que permitió incorporar nuevos modelos teóricoanalíticos, que favorecieron iniciar la etapa de superación de la predominancia de enfoques geopolíticos reduccionistas (equilibrio y balance de poder), y la aplicación de enfoques más comprensivos, abarcadores, integradores y multi causales.

Según algunos autores, Brasil es ahora -bajo el gobierno del presidente Menem- uno de los ejes de la estrategia de inserción internacional de Argentina, constituyendo, en la primera etapa (1989-1995), el aspecto regional de la política "occidentalista", pues, al mismo tiempo que se avanza en la consolidación del proceso de integración económica y de 
cooperación política con Brasil, se profundiza, simultáneamente la estrategia de acercamiento bilateral con Estados Unidos, en temas estratégicos, políticos y económicos. El papel que se asigna al Brasil, en la segunda etapa (que comienza en 1996 y podría haberse proyectado de conseguirse la re-reelección presidencial), es el de integrarse a una alianza conjunta con Argentina, los Estados Unidos y la OTAN (de la Balze,1995:15).

Claramente, para un sector importante de la inteligencia y de formuladores de política, Brasil ha adquirido un carácter instrumental para la inserción internacional argentina, siempre y cuando cumpla con los requisitos asignados por los objetivos de la política exterior pro occidentalista y de alineamiento con Estados Unidos.

En este camino la cooperación política ha mostrado progresos. "En lo político y en lo estratégico, el diálogo bilateral se ha distendido y profundizado; las tradicionales hipótesis militares de conflicto han desaparecido gradualmente y los niveles de confianza mutua se han incrementado sustancialmente (...). Sin embargo, subsisten diferencias relevantes en las visiones que cada uno de los países tienen sobre el escenario internacional y sobre su estrategia de inserción en el mundo político y estratégico contemporáneo. Asimismo, en el área de lo político-estratégico los progresos alcanzados generan nuevos y complejos desafíos"3.

El análisis de la relación económica puede revisarse a través de los progresos comerciales en el Mercosur, aunque los escasos progresos en aspectos más estructurales e institucionales del mismo tienen relación con las diferencias de interpretación sobre el papel del Mercosur en las respectivas estrategias nacionales de desarrollo e inserción internacional ${ }^{4}$. En tanto, el seguimiento de la relación político-estratégica bilateral puede analizarse a través de la política bilateral. Según algunos autores, el bajo nivel de conflictividad regional y la modesta importancia de la región en el proceso de reordenamiento mundial postguerra fría favorece el proceso de integración y cooperación bilateral (de 1a Balze,1995; Escudé y Fontana,1998;1998a). En ambos países el establishment y las dirigencias

\footnotetext{
3Felipe A.M. de la Balze, "Argentina y Brasil: Enfrentando el Siglo XXI", p. 106.

${ }^{4} \mathrm{Hemos}$ hecho referencia a estos temas en tres trabajos, uno anterior a la llegada al gobierno del presidente Cardoso y otros dos durante su gestiōn. Cfr., Raûl Bernal-Meza, América Latina en la Economía Política Mundial, Tercera Parte; "El Mercosur y el Área de Libre Comercio de América Latina en el contexto de la Regionalización y la Globalización" (1997), y "As relaôes entre Argentina, Brasil, Chile e Estados Unidos: Política Exterior e Mercosul" (1998a).
} 
políticas perciben la integración económica como una prioridad política. Sin embargo, es conveniente recordar que tal percepción coincide con un período de proliferación de acuerdos regionales de liberalización de comercio y de integración, particularmente en el caso de América Latina ${ }^{5}$.

El mayor acercamiento de Brasil a Estados Unidos (tema fundamental para el gobierno argentino) comenzó bajo la presidencia de Collor de Melo, con un modelo de política económica en consonancia con las líneas neoliberales predominantes en México, Argentina y Chile. En ese marco de mayor acercamiento de las posiciones brasileñas a las de Estados Unidos y sus principales aliados, "se inició un vigoroso proceso de aproximación y coordinación entre Argentina y Brasil en los temas de armamentos de destrucción masiva y un genuino esfuerzo por aumentar la confianza mutua"6.

\section{El cambio de enfoques y paradigmas de política exterior en Argentina:}

Desde la perspectiva de los formuladores y decisores de política de la administración Menem, como el mundo cambió hubo que adecuarse a las nuevas reglas de la economía y la política mundiales (Bernal-Meza, 1998;1998a). Las políticas, por tanto, debían ser orientadas en función de lograr la integración en las nuevas normas internacionales resultantes del nuevo orden de poder mundial. Como ha descripto otro autor, para estos decisores, "el mundo se organiza en base a otras reglas desde el Fin de la Guerra Fría. El peso de la economía y la legitimidad de las reglas del derecho remiten a la conformación de un mercado universal gobernado por la democracia"7. Para ello se trabajó sobre dos pilares: la política comercial, tratando de mostrar previsibilidad, estabilidad y apertura; por el otro, en el campo de la seguridad, tratando de eliminar conflictos y sobre todo cambiar el perfil frente a los asuntos de la

${ }^{5}$ Además estos acuerdos se han generalizado en una época en donde Estados Unidos ha puesto nuevo énfasis en la estrategia del regionalismo. Cfr. Roberto Bouzas, "Introducción", en BOUZAS, Roberto (Comp.), Regionalización e Integración Económica, Buenos Aires, Grupo Editor Latinoamericano/ ISEN, 1997.

6Felipe A.M. de la Balze, op. cit., p. 108.

7Ruth Diamint, "Agenda de Seguridad de Argentina" (1998), p. 5. 
proliferación (Diamint,1998). La expresión regional de esa conducta sería la superación de rivalidades históricas con Brasil, la generación de medidas de transparencia, el establecimiento de consultas y los intercambios civiles y militares.

Según Escudé y Fontana, tres premisas sustentan el cambio de políticas:

1.- En una democracia liberal, en circunstancias que la política de antagonismo con Estados Unidos implicó costos para el país, la principal función de la política exterior debiera ser la de servir a los ciudadanos individuales, y ésto se consigue facilitando el desarrollo económico.

2.- El desarrollo económico es la definición misma de interés nacional, especialmente en un país en vías de desarrollo que no enfrenta amenazas externas creíbles.

3.- Los Estados Unidos constituyen la limitación externa individual más importante para la política exterior de los países latinoamericanos y, por lo tanto, es del mejor interés tener buenas relaciones con esa potencia, siempre que estas buenas relaciones no sean a expensas de los intereses materiales de la Argentina (Escudé y Fontana,1995:5).

Desde la actual formulación y conducción de la política exterior argentina se visualiza el sistema internacional como pleno de oportunidades y no se perciben amenazas estratégicas relevantes, con excepción del terrorismo, considerándose la relación con Estados Unidos un elemento clave. Por lo tanto, cualquier desafío al liderazgo norteamericano que no esté vinculado al desarrollo argentino es contraproducente. Toda aspiración de ejercer influencia sobre la agenda internacional es a través de una estrategia de desarrollo y alineamiento explícito, como lo hicieron Japón y Alemania.

\section{A.- La construcción del modelo de política exterior argentina:}

Argentina, bajo el gobierno del presidente Menem abandonó las políticas que perciben al país como un actor en un mundo donde las relaciones internacionales están descriptas por las premisas del modelo realista de relaciones internacionales y optó por las del tipo ideal del trading states.

La política exterior argentina, según académicos de gran incidencia en su formulación, es ciudadano-céntrica. Para Escudé y Fontana (1995; 
1998;1988a), la política exterior argentina actual es lo esperable de lo que Richard Rosecrance ${ }^{8}$ ha llamado trading states. Esta política no puede ser interpretada razonablemente como una amenaza a su seguridad por los países vecinos y, en particular, por Brasil.

\section{B.- Los cambios en la política de seguridad:}

\section{- Respecto de la seguridad global:}

El principal eje de las políticas argentinas radica en su apoyo a las Naciones Unidas y a su Consejo de Seguridad, a la vez que está alineada con Occidente.

El objetivo de "cooperar" con la OTAN fue un second best. El objetivo primero era integrarse a ella.

La política nuclear se fundamenta en la idea que haya un número mínimo de Estados nucleares que se constituya en el grupo oligopólico que use su poder para evitar la ampliación del número. Este grupo oligopólico es apoyado por la Argentina9.

\section{- Las políticas de seguridad regional:}

Las políticas argentinas pueden resumirse en los siguientes propósitos: 1) apoyar los esfuerzos del Secretario General de la ONU para promover una diplomacia preventiva y de cooperación de las agencias y regímenes regionales con las Naciones Unidas; 2) el sistema de seguridad colectivo requiere el apoyo de los regímenes regionales (hemisféricos, latinoamericanos) y la legitimación de éstos sólo puede ser dada por un vínculo sólido

\footnotetext{
"Sobre los dos tipos ideales de Estado, el "Estado comercial" y el "Estado politico-militar-territorialista", ver Richard Rosecrance, The Rise af the Tradig State, Basic Books, New York, 1986, pp. 22-44. Refiriéndose al "Estado comercial", o "Estado generente", Roberto Russell señala que la influencia se obtiene a travếs del liderazgo industrial y científico. "En este marco, los nuevos rivales desplegarán sus armas y librarán sus batallas en el campo Mercurio y no en el de Marte. Así, su comportamiento estará propablemente mucho más cerca del tipo ideal Estado comercial que del tipo Estado políticomilitar-territorialista y, por consiguiente, procurarán robustecer su poder político a través del incremento de la fortaleza económica y no del poder militar" (Roberto Russell, "El contexto externo de la política exterior argentina: notas sobre el nuevo orden mundial", en R. RUSSELL (1992a:28). De estas palabras se desprende que los conceptos clásicos de autonomía, soberanía y territorio han sido vaciados de contenido, en beneficio de los conceptos nuevos de "especialización", "interdependencia", "seguridad colectiva", etc.

${ }^{9}$ Como puede advertirse con el conocimiento de los ejemplos conocidos (India y Paquistán) y otros menos conocidos pero supuestos (Israel, Corea del Norte, Irán), este objetivo ha sido un fracaso.
} 
con las Naciones Unidas; 3) La Argentina coincide con la visión norteamericana sobre la necesidad de desarrollar un nuevo concepto de seguridad regional: el de la seguridad cooperativa;

Sin embargo, podría señalarse que la evidencia de que aún no ha surgido una visión alternativa (integración y cooperación) que anule por completo la vigencia de los enfoques geopolíticos de la política de poder en ambos países, está en el conflicto surgido por el sillón en el Consejo de Seguridad de las Naciones Unidas.

En el pensamiento político-militar argentino existen, sin embargo, matices. Dentro del panorama global se observan tres lecturas: a) aquella que percibe incertidumbre sobre el presente; b) la que subraya la importancia de los conflictos; c) la que destaca los avances logrados en cooperación en materia de seguridad. De aquí derivan dos líneas: una que pone de relevancia los peligros y otra que ve un mundo lleno de oportunidades (Buchrucker,1997). En particular, abordando el marco regional, dentro de un contexto global por cierto, según Buchrucker, en los trabajos que se aplican a los temas de seguridad, tanto de civiles como de militares, "se descubre un avance importante: la cuestión acerca de quién define la amenaza para luego convertirla en base de una política de defensa ya no está envuelta en la peligrosa ambigüedad que era habitual en los años 60 y 70; hoy todos los analistas, tanto civiles como militares, concuerdan en que esa es una función eminentemente política (...) y como tal, también sujeta a discusión. Sólo los textos de origen carapintada ${ }^{10}$ mantienen la vieja pretensión arrogante de imponer a la nación una percepción de amenaza al margen y aún en contra del consenso mayoritario" (Buchrucker,1997:15).

\section{Las distintas políticas exteriores de Argentina y Brasil:}

Se tiene la idea que las diferencias que separan actualmente a Argentina e Brasil son sustancialmente referidas a los distintos enfoques sobre la Seguridad. Sin embargo, las que dan basamento a éstas y que constituyen lo medular de la reformulación de la política exterior argentina bajo el gobierno del presidente Menem se relacionan con las interpretaciones, las concep- 
ciones y visiones de mundo que, como paradigmas, dan base a nuevas prescripciones teórico-analíticas para la formulación de la política exterior.

En el primero de una serie de estudios referidos a los problemas de Seguridad en el Cono Sur, Escudé y Fontana (1995), parten del principio que con el advenimiento de Menem las políticas exterior y de seguridad de la Argentina cambiaron drásticamente. La argumentación, tradicional ya en el pensamiento de Escudé (1992;1995), es que Argentina deja atrás una historia de antagonismo sistemático con Estados Unidos ${ }^{11}$, que tenía su sustento en la política de poder seguida por el país, y adopta un nuevo modelo, el de la política de bienestar, centrada en el enfoque ciudadano-céntrico.

Según estos autores, en Argentina se termina el consenso sobre los ejes importantes de las políticas exterior y de seguridad, respecto de una política de desarrollo nuclear y estratégico. "Este consenso aún prevalece en Brasil y es una de las causas de las divergencias estratégicas que actualmente dividen a los Estados argentino y brasileño" (Escudé y Fontana,1995:7).

Estos cambios llevados a cabo por Argentina son resultado de la nueva concepción de la política exterior, bajo las gestiones de Cavallo y Di Tella, de alineamiento explícito con los Estados Unidos. Argentina cambió completamente el perfil de sus votos en los foros intergubernamentales, adoptando una política claramente pro-occidental, plegándose a algunas políticas de seguridad norteamericanas " (Escudé y Fontana,1995:4).

Si uno aplica la lógica del discurso de los formuladores (ideólogos y teóricos) de la política exterior argentina, este país, bajo el gobierno del presidente Menem, ha apoyado las decisiones del Consejo de Seguridad de la ONU; se ha alineado explícitamente con Estados Unidos y "el club de países occidentales"; ha tenido una intensa participación en operaciones de paz, habiendo -previamente-participado en la Guerra del Golfo, siendo pionera de la intensa participación y presencia latinoamericana en operaciones de paz ${ }^{12}$. Es decir, ha hecho todo lo que Brasil no ha hecho. La lógica

"Tanto Escudé como J. Tulchin han hecho referencia a este antagonismo. Cfr. Escudé (1992;1995) y Tulchin (1990) 12 "La participación en misiones de paz (1765 participantes en 1994, contra 138 de Brasil) ha proyectado una imagen de Argentina como un país confiable, comprometido con la paz y la seguridad internacionales, premisa convalidada empíricamente por un creciente número de reacciones positivas de parte de los establishments militares de diversos Estados -los miembros de la OTAN en particular" (Carlos Escudé y Andrés Fontana, "Las políticas de seguridad de Argentina: sus fundamentos y contexto regional", en Jorge Domínguez (Editor), Seguridad Internacional, Paz y Democracia en el Cono Sur, Santiago, FLACSO, 1998; pp. 91-92). 
es que Brasil no hace nada de lo que hace Argentina y por eso hay una percepción de desconfianza (internacional) hacia Brasil.

\section{Percepciones sobre las relaciones Brasil-Estados Unidos:}

Desde la percepción argentina predominante en los círculos de poder, Brasil pasó de una relación de alineamiento y estrecha cooperación con Estados Unidos, que se extendió hasta mediados de los años 70, a otra de conflicto, derivada de la proyección de sus aspiraciones como potencia regional. La base de las estrechas relaciones con Estados Unidos habían sido los temas de seguridad hemisférica y regional.

Las relaciones militares entre los Estados Unidos y Brasil tenían como base el acuerdo de cooperación de 1952, que sería abandonado por Brasil en 1977, bajo el gobierno militar de Ernesto Geisel.

Según la visión de la conducción de la política exterior argentina actual, Brasil considera que el auténtico problema de seguridad para los países del Cono Sur proviene de los Estados Unidos. Citando puntos de vista expresados por altas personalidades militares brasileñas, Estados Unidos tiene políticas hegemónicas que son apoyadas por Argentina. La Pax Americana, bajo un proyecto de seguridad interestatal, es para Brasil, según autores argentinos, una política de hegemonía de Estados Unidos.

Sin embargo, existen diversos fundamentos objetivos para la interpretación de las dificultades actuales en las relaciones entre Brasil y Estados Unidos (Bernal-Meza,1998;1998a), que no son tenidas en cuenta por el actual establishment de gobierno y poder en Argentina.

Según un autor argentino, hay tres temas conflictivos en la agenda brasileño-norteamericana: 1) Amazonia: Ciertos legisladores estadounidenses han propuesto -bien que sin éxito- desplegar una fuerza internacional para impedir la depredación del último pulmón verde del continente; 2) Armas: Brasil firmó en 1992 el Tratado de Tlatelolco, pero se ha reservado el derecho a desarrollar tecnología atómica para la propulsión de naves de guerra; 3) Narcotráfico: El Pentágono ha firmado acuerdos con las Fuerzas Armadas de Perú, Colombia y Bolivia para que se concentren en la lucha contra el tráfico de estupefacientes. Los militares brasileños no se oponen a combatirlo pero desconfían de la política norteamericana, que ven 
interesada en reducir su papel al de fuerzas de seguridad (Massot,1995).

Un segundo nivel de conflictos está en lo que el almirante Mario Flores ha señalado como a nova política dos Estados Unidos e de outros países democráticos de regularem suas relaçôes externas en funçâo da práctica da democracia ${ }^{13}$.

Un tercer nivel de conflictos se lee a través del (supuesto) debilitamiento de la capacidad militar brasileña, impulsado por los Estados Unidos, utilizando la política de seguridad y las apelaciones a la democracia. Señala al respecto un autor argentino que "Brasil parece comprender que la integración reduce los antagonismos e induce a tomar medidas de confianza mutua de resultas de las cuales, tarde o temprano, las Fuerzas Armadas de los distintos países deberán estar preparadas para asumir roles regionales, previamente establecidos entre los respectivos Estados. Pero ve con singular preocupación -no registrada con la misma intensidad entre nosotros- el fenómeno de la reducción de la capacidad de defensa de los países del subcontinente que, en la práctica, termina obrando (en favor de) una absorción de esa capacidad en beneficio de una gran potencia que asumiría como propia la defensa continental. Las formas en que se da este fenómeno son de dos tipos: por un lado, la idea de que, con el ajuste de las economías regionales, deben reducirse a su mínima expresión los presupuestos militares en función de que no hay más guerras que pelear $y$, si acaso las hubiese, la potencia hegemónica del continente se encargaría de ponerles coto; por el otro, la concepción según la cual las Fuerzas Armadas deben evolucionar hasta convertirse en fuerzas de seguridad para combatir el narcotráfico, el contrabando, el terrorismo y defender la democracia. Al extremo de que no han faltado voces -ciertamente no brasileñasque han impulsado la idea de formar una fuerza interamericana de intervención rápida para sostener la democracia allí donde ésta se hallase en peligro. Semejante intento tardío de resucitar la Santa Alianza -sólo que con colatura democrática- se contrapone de manera acabada con los dos pilares que siguen rigiendo la política exterior de Itamaraty: la autodeterminación de los pueblos y el principio de no intervención en los asuntos de otros Estados" (Massot,1995:235). 
Según Escudé y Fontana (1998;1998a), los brasileños piensan que el concepto de seguridad cooperativa es el aspecto militar de la política hegemónica norteamericana, en un contexto de globalización y de un ensanchamiento de las diferencias entre ricos y pobres.

El concepto de seguridad cooperativa ${ }^{14}$ cristaliza la hegemonía de Estados Unidos y avanza hacia la disolución de la soberanía de los Estados (Escudé y Fontana,1998a:72). Para estos autores, según la opinión de sectores de la inteligencia, las fuerzas armadas y diplomáticos brasileños, hay claramente una confrontación potencial entre la Cuenca del Plata y el Norte. Escudé y Fontana consideran que los brasileños están en contra de la implementación de las políticas de seguridad norteamericanas porque las perciben también como amenazas a los intereses de sus complejos industriales-militares.

Las diferentes perspectivas estratégicas entre Brasil y Estados Unidos (por tanto también con Argentina) están condicionadas por las diferentes circunstancias que enfrentan Brasil y Argentina, entre ellas: la mayor vulnerabilidad financiera argentina, la importancia interna de la industria brasileña de armamentos y el peso de ésta en su comercio exterior.

Brasil tiene un conflicto de intereses con Estados Unidos por el comercio internacional de armas ${ }^{15}$ y sobre comercio bilateral. Según otros analistas argentinos, ubicados en el pensamiento de la "oposición"16, las relaciones entre Brasil y Estados Unidos son muy complicadas. Las discrepancias superiores a lo tradicional derivan del hecho que Estados Unidos quiere disciplinar económicamente a toda América Latina, a través de ALCA, cuestión que los brasileños rechazan.

\footnotetext{
${ }^{24}$ Una contribución importante al desarrollo del concepto de "seguridad cooperativa" se encuentra en trabajos del programa de investigaciones de FLACSO.Chile; ver, Augusto Varas, "La seguridad hemisférica cooperativa de postguerra fría", Paz y Seguridad en las Américas, Santiago, FLACSO, 1994. También, los documentos del Programa Paz y Seguridad en las Américas: "Políticas de seguridad hemisférica cooperativa, recomendaciones de política", Santiago, FLACSO, marzo 1995.

"Esta es una oponión que comparten tanto autores argentinos (Escudé, Fontana), como brasileños, tal el caso de Amado Luiz Cervo, quien lo expresara asi recientemente en entrevistas en Buenos Aires, a mediados de agosto de 1998.

${ }^{16}$ Por ejemplo, Atilio Borón.
} 


\section{Una visión general desde Argentina sobre Brasil, sus relaciones internacionales y su política exterior:}

Para la inteligencia vinculada a la formulación de política exterior y para los formuladores de ésta en Buenos Aires, 1a visión del mundo que tiene Brasil es equivocada, por tanto también sus aprehensiones respecto de la seguridad y el desarrollo posibles en un mundo global. Se considera que una parte importante de los sectores brasileños nacionalistas más influyentes creen que existe un conflicto político, económico y tecnológico entre el Norte y el Sur y éste será el conflicto central de las próximas décadas ${ }^{17}$.

Una segunda interpretación fundamental sobre Brasil es que el mundo de la postguerra fría y de la (supuesta) globalización, dejó obsoleto el objetivo brasileño de ser considerado una potencia ${ }^{18}$. Según De la Balze, el fin de la guerra fría y los cambios en el escenario político-económico mundial dejó en el pasado el concepto de potencias regionales que había sido legitimado por el orden anterior. "El no reconocimiento de su condición de gran potencia regional por importantes vecinos como la Argentina, Chile, Colombia y Venezuela, una indiferencia activa por parte de Estados Unidos y la falta de consenso en el seno de las naciones Unidas podrían

"Esta tambiên es la opinión expresada en Buenos Aires por importantes funcionarios de Itamaraty. en una disertación en la Universidad de Buenos Aires, el 19 de agosto de 1998, el embajador Samuel Pinheiro Guimarâes se expresó en idênticos términos.

${ }^{8}$ Es interesante destacar que los analistas argentinos que se ubican en esta óptica y que están muy bien informados sobre los temas de debate de la polítca internacional a nivel mundial, no hayan hecho hasta ahora ninguna mención a la reformulación del concepto potencias regionales, bajo el nuevo concepto de Estados-pivot, en el cual sus formuladores han incluído precisamente a Brasil y no a la Argentina. Según éstos, las nuevas realidades surgidas como consecuencia del fin de la Guerra Fría, han puesto de relevancia nuevos problemas (y temas de la agenda), que realzan la importancia de otros paises. La idea de que las decisiones de un Estado-pivot podrian afectar la estabilidad internacional no es nueva; sin embargo, para los autores, el sentido que hasta hace unos años dieron los diseñadores de políticas norteamericanos, desde Eisenhower y Acheson a Nixon y Kissinger, sobre países que al sucumbir al comunismo provocaran un "efecto dominó", mantiene su lógica, en el sentido de que habría que identificar países específicos que son más importantes que otros, tanto para la estabilidad regional como para los intereses norteamericanos; una concepciôn de política que llevaría a Estados Unidos a concentrar su ayuda e interés en ellos y no desparramando sus recursos por todo el Globo. Estos nuevos Estados-pivot no necesitan más de asistencia contra la amenaza externa de un sistema político hostil, sino para prevenir los riesgos derivados de sus propias condiciones internas que, dadas sus características geo.económicas, son muy importantes para la seguridad. Entre éstos está Brasil, cuyo potencial económico, su identificaciôn como uno de los "grandes mercados emergentes", su enorme extensión y población, permiten ubicarlo en esa categoría. En particular, lo que define a un Estado-pivot es ese conjunto de características, por las cuales su colapso acarrearía desorden y confusión más allá de sus fronteras, mientras que su estabilidad sostendria la vitalidad económica y la coincidencia política de su región, beneficiando asi el comercio y la inversión norteamericana. Cfr. Kennedy, Chase, Hill (1996). 
frustrar la ambición brasileña, al menos en el futuro inmediato"19. Según este autor, la propia dinámica del proceso de reformas estructurales en curso en Brasil y el programa económico favorecen un gradual realineamiento de la política internacional de Brasil hacia una mayor cooperación con Estados Unidos, un menor énfasis en el conflicto Norte-Sur y una paulatina reducción de la importancia de los sectores militares en la determinación de la estrategia internacional del país. Además, la preeminencia en lo económico genera una nueva convergencia potencial entre los Estados Unidos y los países del Mercosur (De la Balze,1995).

- Se considera que la inexistencia de un ministerio de defensa en Brasil es un obstáculo para la cooperación y la coordinación en el campo de la seguridad (Bernal-Meza,1998;1998a; Escudé y Fontana, 1995, 1998, 1998a). La autonomía de los ministerios para cada una de las tres fuerzas armadas brasileñas ayuda a los militares brasileños a escapar parcialmente del control civil (Escudé y Fontana,1995:13).

- Brasil no representa un peligro militar para la Argentina, ya que se supone que sus ambiciones radican en otras esferas: económica y de reconocimiento de su papel como potencia regional por parte de las grandes potencias.

- Brasil no parece comprometido con el control formal de armas convencionales y con auténticas medidas de generación de confianza en este campo (Escudé y Fontana,1995;1998;1998a).

- En Brasil no existe animosidad cívico-militar. El gobierno y el establishment diplomático pueden ser descriptos como "leales socios de la corporación militar. y de su poderoso apéndice, la industria militar de armamentos" (Escudé y Fontana, 1995:18).

- Brasil es contrario a la institucionalización de medidas de confianza mutua con Argentina. Acepta y practica medidas de confianza, pero no acepta CBMs, porque considera que no hay necesidad. El requisito previo a la cooperación es que los norteamericanos sean mantenidos lo más lejos posible.

- La hipótesis es que las CBMs y las reducciones de armas son percibidas por los brasileños como una amenaza a los intereses de sus corporaciones e industrias militares, por lo que la Argentina y sus propuestas sobre seguridad son un modelo peligroso a los intereses de los militares brasileños ${ }^{20}$.

${ }^{19}$ De la balze, op. cit., p. 114.

${ }^{20} \mathrm{En}$ los trabajos de Escudé y fontana $(1995 ; 1998 ; 1998 \mathrm{a})$ no hay diferencias en este punto, entre el gobierno de Franco y el gobierno de Cardoso. 
- Sin embargo, el principal impedimento al cambio de política en Brasil obedece a las condiciones sociales y políticas internas. Se considera que su sociedad, al ser considerablemente menos democrática -política, social y distributivamente- sus élites y el establishment se sostienen en el recurso a la acumulación estatal de poder.

- Para los formuladores de la política exterior argentina actual y su sustento ideológico-político, Brasil no puede adoptar el enfoque ciudadanocéntrico porque es un país oligárquico. Es, también muy sensi-ble a la erosión de la soberanía, porque se siente afectado por objetivos que atañen a su seguridad territorial, como es el caso de la Amazonía y porque su mercado de exportación de armas -con un socio tan importante como Irán- no le permite adherir a los nuevos conceptos de seguridad ${ }^{21}$. Este punto de vista sobre las características conservadoras del Brasil también es compartido por Torcuato Di Tella, para quien las condiciones de su desarrollo, la existencia de un amplio sector de mano de obra barata y subocupada, crea un contexto social y político muy distinto al de la Argentina. Para este autor, el hecho de que "en el vecino país se han dado las condiciones para lo que Arthur Lewis llama una industrialización con oferta ilimitada de mano de obra" (Di Tella,1995:6) ${ }^{22}$, ha retrasado el proceso de construcción de una sociedad con presencia fuerte del sindicalismo y de partidos políticos populares, a diferencia de lo que fue el caso argentino.

\section{Una síntesis de los puntos de conflicto que, desde la perspectiva argentina, afectan las relaciones Argentina-Brasil:}

Como ha podido observarse a partir de los análisis precedentes, Argentina y Brasil tienen concepciones sobre el mundo, el nuevo orden mundial y la seguridad muy diferentes, como así también estructuras socio-

2'Siguiendo el análisis de Escudé y Fontana, teniendo en cuenta los atentados sufridos por Argentina que se adjudican a una "pista iranī", la vinculación Brasil-Irán podría transformarse en la dimensión brasileña de las amenazas a la seguridad argentina. Este hecho, de llegar a producirse un nuevo atentado, podría poner en muy dificiles têrminos las relaciones brasileño-argentinas.

${ }^{22}$ Torcuato Di Tella identifica un contraste en las estructuras sociales brasileñas y argentinas. Cfr. Di Tella $(1995: 5 \cdot 9)$. 
económicas distintas, to que permite, en el caso argentino, el sustento de concepciones sobre las políticas de Estado ("ciudadano-céntricas"), pero no en Brasil. De ello se desprende que mientras algunas variables como el tipo de régimen sean consideradas hoy en Buenos Aires como un argumento de intervención (como es el caso de la democracia), para Brasil esto es absolutamente inaceptable.

De hecho, se piensa que los brasileños consideran como un esfuerzo por resucitar la Santa Alianza el hecho de recurrir a la democracia, su defensa o sostenimiento, como fundamento de intervención. Esto pone en oposición dos principios que para Itamaraty siguen siendo pilares de sus principios de política exterior: la autodeterminación y la no intervención en los asuntos de otros Estados, cuestiones que para la actual política exterior argentina son relativas.

Los puntos más importantes de conflicto se centran en:

1.- Siendo para la Argentina fundamental su relación de alineamiento con Estados Unidos, que se explica por la comprensión del hecho que la limitación externa individual más importante para las políticas exteriores latinoamericanas es Estados Unidos y que el camino para ejercer influencia en la agenda internacional es a través de esa potencia, cualquier política exterior de un país importante -como es el caso de Brasil- que no se asocie a la visión argentina no es funcional a su interés nacional. Brasil adquiere para Argentina un carácter instrumental en su inserción internacional y en la consolidación de las relaciones argentinas de amistad y cooperación con Estados Unidos. Esto lleva a Argentina a buscar limitar cualquier nivel de confrontación eventual de Brasil con Estados Unidos, lo que explica los esfuerzos por plegar a Brasil a la política global y hemisférica de seguridad norteamericanas.

2.- Desde una perspectiva argentina de corto plazo, la prioridad de la relación con Brasil no es en detrimento de una relación privilegiada con los Estados Unidos, ya que mejores relaciones con los Estados Unidos amplían la capacidad de diálogo con Brasil y viceversa. Desde una perspectiva de mediano plazo esta estrategia, según autores argentinos, es coherente y beneficiosa para ambos países sólo si Brasil se incorpora plenamente a la estrategia de acercamiento iniciada por la Argentina con los Estados Unidos (de la Balze,1995:16). Por lo tanto, hay una necesidad y conveniencia de que la Argentina y Brasil desarrollen, 
conjuntamente, relaciones privilegiadas preferenciales con los Estados Unidos, a través de la creación de una zona de libre comercio hemisférica y de una alianza en temas estratégicos y militares, así como con la Unión Europea. Esto supone que Brasil no puede asumir roles ni políticas que sean conflictivas con Estados Unidos.

3.- La persistente influencia de los intereses militares y las concepciones geopolíticas en países vecinos (Brasil, Chile) es un obstáculo para la puesta en práctica de la política exterior argentina (Escudé y Fontana,1995:11-12).

4.- El Mercosur; la creciente interdependencia económica y política con Brasil representa una amenaza al alineamiento de la Argentina con Occidente (Escudé y Fontana,1995:5).

5.- Subsisten diferencias relevantes en las visiones que cada uno de los países tiene sobre el escenario internacional y sobre su estrategia de inserción en el mundo político y estratégico contemporáneo (de la Balze,1995). Las principales divergencias entre Argentina y Brasil surgen de las distintas concepciones del pensamiento estratégico de ambos países. Comprendiendo que éste constituye uno de los puntos claves sobre las diferencias bilaterales, vale la pena revisar éstas desde la perspectiva de algunos autores que han hecho un seguimiento del tema.

Para De la Balze, subsisten aún diferencias importantes entre Argentina y Brasil respecto de sus visiones estratégicas globales de la política mundial. Las principales diferencias respecto de los temas centrales de la política mundial se aglutinan alrededor de dos grandes temáticas: por un lado, en percepciones diferentes de la potencial amenaza externa y su correlato, la estrategia de seguridad, y, por otro lado, en la definición de Jos niveles de conflictividad y cooperación que caracterizan las relaciones Norte-Sur y la naturaleza de la relación a desarrollar con los países avanzados, en particular con los Estados Unidos (de la Balze, 1995:111).

La política de seguridad implementada por el gobierno argentino actual tiene como objetivo fortalecer las políticas de seguridad colectivas impulsadas por los Estados Unidos, en colaboración con las Naciones Unidas. Asimismo, la Argentina comparte la nueva visión sobre la seguridad regional, identificada bajo el concepto de "la seguridad cooperativa" y promovida por los Estados Unidos. 
Argentina se ha transformado en una entusiasta impulsora de los nuevos mecanismos de seguridad: no proliferación de armas de destrucción masiva, medidas de fomento de la confianza, prevención de conflictos y fortalecimiento del control civil sobre las estructuras militares nacionales.

Desde esta lectura, la posición brasileña no puede ser más diferente. Apoyándose en el pensamiento de Mota Sardenberg (1995) y en expresiones de altos funcionarios de Itamaraty, se concluye en Buenos Aires que el Brasil ve el nuevo contexto internacional tanto como un mundo de oportunidades potenciales y relativas, así como una fuente potencial de riesgos y amenazas para la seguridad y el desarrollo de los países periféricos.

Según Escudé y Fontana, la ideología que predomina entre los establishment gubernamentales, diplomáticos y militares brasileños es totalmente diferente a la que predomina en Argentina. Este contraste en el pensamiento estratégico ha conducido a enérgicos intentos brasileños de adoctrinar a los funcionarios argentinos con lo que para ellos es la buena doctrina (Escudé y Fontana,1995;1998;1998a), y "el Mercosur se ha transformado en un terreno fértil para su mensaje en segmentos significa-tivos de la sociedad y burocracia argentinas" (Escudé y Fontana,1995:23). Esta preocupación surge porque los brasileños encuentran suelo fértil en sectores influyentes de la sociedad y burocracia argentinas para su mensaje, gracias al alto grado de afinidad cultural, la creciente importancia económica y política del Mercosur y de la cooperación militar bilateral.

Haciendo una revisión del "mensaje brasileño", explicitado en la visita de varias delegaciones a los que Escudé y Fontana remiten, éste se fundamenta en los siguientes puntos relevantes:

- Ya no existen razones para temer un peligro a la seguridad desde países vecinos, un tema que en lo que se refiere al Brasil la Argentina está de acuerdo.

- Por lo tanto, para los brasileños, no hay necesidad de progresos adicionales en términos de control de armas convencionales y del establecimiento de mecanismos de seguridad cooperativa, algo en la que la Argentina de hoy discrepa totalmente.

- Para Brasil, el auténtico problema de seguridad para los países del Cono Sur proviene de Ios Estados Unidos, fundamentación en la que 
Argentina está en absoluto y total desacuerdo " (Escudé y Fontana, 1995:23) ${ }^{23}$. La Pax Americana, bajo un proyecto de seguridad interestatal, es una política de hegemonía de Estados Unidos, apoyado por Argentina.

- La Argentina y sus propuestas sobre CBMS y las reducciones de armas son un modelo peligroso a los intereses de los militares brasileños; percibidas como una amenaza a sus corporaciones e industrias militares. Sin embargo, se señala que detrás de esta defensa está el condicionamiento de persistentes delirios de grandeza sobre su futuro como potencia mundial, no muy diferentes a los que afectaron a la Argentina en el pasado ${ }^{24}$. Entre éstos está su aspiración a ocupar un sillón en el Consejo de Seguridad de las Naciones Unidas, a lo que Argentina se opone, no porque esté contra el Brasil, sino porque ello contradice sus ideas acerca de la gobernabilidad del orden interestatal.

- Las diferencias en el pensamiento estratégico de los gobiernos de Argentina y Brasil están en cierta forma condicionadas por las diferentes circunstancias e intereses de ambos países, en las cuales se incluyen grados de vulnerabilidad financiera, el peso de la industria militar, las percepciones sobre la erosión de la soberanía estatal, etc.

${ }^{23}$ Segûn Escudé y Fontana, las argumentaciones brasileñas, claramente expuestas en Buenos Aires, se sintetizan en expresiones del general Manuel Texeira, el almirante José do Amaral Oliveira, el coronel Morgado y el Dr. Antonio Carlos Pereyra. Según los autores, en el seminario "Fuerzas Armadas 2000", llevado a cabo en Buenos Aires el 28 de junio de 1994, "se señaló claramente que el problema más importante enfrentado por los países de la región provenía de la combinación del subdesarrollo con la política hegemónica de los Estados Unidos. Se afirmó que esta política hegemónica tenía lugar en un contexto de globalización económica y de un ensanchamiento de la brecha entre los países pobres y los países ricos, y que entre otros mecanismos para mantener el status quo los Estados Unidos operan para obstruir la adquisición de alta tecnología por parte de países como la Argentina y Brasil. Más aún, se alegó que el aspecto militar de esta política es el concepto de seguridad cooperativa, que cristaliza la hegemonía de los Estados Unidos y avanza hacia la disolución de las soberanias estatales, que ya se encuentran adversamente afectadas por el proceso de globalización económica. Por consiguiente, estân en contra de cualquier propuesta para la construcción de un sistema hemisférico de seguridad estatal. En su opinión, los países afectados por estos intentos hegemónicos deben unirse a los efectos de estar en una mejor posición frente a los poderosos; deben resistir todos los intentos de subordinar o debilitar sus instituciones militares; deben mantener sus identidades nacionales claramente diferenciadas, y muy especialmente, deben obtener acceso a la alta tecnología que les es negada.

“Más específicamente, el Dr. Liverio Pereyra, presidente del IBAE, señaló el peligro de la erosión de las soberanias nacionales. Existe según êl una contradicción entre la globalización económica y la seguridad nacional, enfatizando que aún no ha sido suficientemente discutido el papel que los paîses de la región le permitirán jugar a los Estados Unidos. Enfatizó los intentos hegemónicos de los Estados Unidos y dijo que claramente existe una potencial confrontación entre el Plata y el Norte" (Escudé y Fontana,1995:23-24).

24Dicen estos mismos autores: "en segmentos significativos de la sociedad brasileña, incluyendo los militares y la dirigencia política, aún sobrevive con fuerza la idea de que Brasil tiene un destino manifiesto como potencia mundial. Cuando les viene bien para seducir a sus vecinos, incluyen al Mercosur en el cuadro" (lbid, p. 28). 
Sin embargo, es coincidente en la visión de los críticos argentinos a la política exterior y de seguridad brasileñas, que la aspiración de Brasil de acceder y ser considerado una potencia mundial es una fuente particular de conflictos potenciales. De la Balze considera que Brasil no podrá transformarse en una gran potencia regional e incrementar su autonomía si no fundamenta dicha estrategia en una estrecha cooperación con la Argentina, en el marco de una integración regional cooperativa. "En mi opinión dice el autor- la búsqueda excluyente por parte de Brasil de una vía separada para alcanzar su autonomía internacional y su desarrollo económico generará rivalidades estériles y artificiales en la región, que imposibilitarán la concreción de ese objetivo"25 y, al igual que Escudé y Fontana, considera que el ejemplo fracasado de la Argentina del período posterior a 1943 debería servir de recordatorio.

$\mathrm{El}$ hecho que Brasil no lleve a cabo ninguna -o escasamente- de las políticas de seguridad de Argentina genera una percepción de desconfianza sobre ese país. Según Escudé y Fontana (1998) en occidente se ve a Brasil como un país donde las concepciones geopolíticas cuentan con prestigio y una influencia considerable, a lo que se agrega el hecho de que los militares en Brasil no fueron desprestigiados por la política implementada, las fuerzas armadas mantienen una vinculación estrecha y armoniosa con las élites políticas y diplomáticas y se han mantenido plenamente integradas al sistema político. Esto hace que el peso e influencia del sector militar en las políticas de seguridad sea grande La vigencia en Brasil de estas concepciones ha sido un obstáculo a la instrumentación de las políticas argentina de seguridad (Escudé y Fontana,1998).

La política brasileña de defensa de 1996 puede estar construida como un medio de alejar a la Argentina de Estados Unidos, pero ella no ha cambiado de ningún modo el "firme alineamiento estratégico del gobierno argentino con Estados Unidos" (Escudé y Fontana,1998a:76). Las diferencias en las concepciones sobre seguridad entre Argentina y Brasil son una limitación objetiva para la creación de condiciones de estabilidad a largo plazo en la subregión y reflejan la asimetría de los progresos en la integración económica y la seguridad. 
Con el advenimiento de Cardoso las políticas de seguridad de Brasil y Argentina han comenzado a converger (Escudé y Fontana,1998:96-97). En esta visión, que los autores consideran generalmente aceptada en Argentina, Cardoso ha moderado la influencia de las visiones del pensamiento dominante en Brasil, manifestado por personalidades como los miembros del Instituto Brasileño de Asuntos Estratégicos (IBEA); y por personalidades como el almirante Amaral, el general Texeira, el periodista Pereyra y el intelectual Helio Jaguaribe. "Brasil ha sido reacio a una instrumentación plena del concepto de seguridad cooperativa, que implica que los Estados renuncien parcialmente a su autonomía en materia de seguridad y se comprometan a sistemas de consulta, coordinación e intercambio de información" (Escudé y Fontana,1998:117).

Teniendo Brasil una percepción de conflicto entre los intereses de los países del Sur y los países del Norte -que la Argentina no ve porque considera que gracias a la globalización este conflicto está superado- Brasil ve la necesidad de acumular poder estatal porque el auténtico problema para ellos es que los riesgos a la seguridad para los países del Cono Sur proviene de Estados Unidos. "Los militares del Brasil perciben toda limitación de su autonomía frente a sus vecinos (por medio de la institucionalización de medidas de confianza mutua) como una ganancia neta para las pretensiones hegemónicas estadounidenses"26.

Las señales de acercamiento y convergencia entre Argentina y Brasil se han dado bajo Cardoso, que ha implementado internamente medidas que refuerzan el control civil, la coordinación entre las tres fuerzas armadas, la difusión pública de la nueva política de defensa nacional, etc. Asimismo, el proceso de acercamiento se ha profundizado con la firma del Memorándum de Entendimiento entre ambos gobiernos en materia de seguridad internacional (abril de 1997). Pero, para sus críticos más importantes, estos acontecimientos no han hecho desaparecer las divergencias en el pensamiento y las percepciones estratégicas de ambos países.

"Puede conjeturarse razonablemente que Cardoso está llevando al país al conocimiento de que en la actualidad es muy costoso y difícil rechazar 
completamente una aceptación de demandas internacionales por transparencia en cuestiones de seguridad y que Brasil ha optado entonces por ofrecer transparencia en un nivel subhemisférico, esto es, con la exclusión de Estados Unidos, en un área geográfica limitada, en la cual pueda aspirar a la hegemonía sin ninguna pérdida real de autonomía vis-à-vis los Estados Unidos u otras grandes potencias, que es lo que realmente quiere evitar" (Escudé y Fontana,1998a:77).

Algunos autores argentinos consideran que Brasil excluyó el tema de "la alianza extra OTAN de Argentina" de su agenda negativa con el objetivo de esperar de Argentina una actitud de apoyo para su candidatura como miembro permanente del Consejo de Seguridad de la $\mathrm{ONU}^{27}$.

De la Balze considera que la creación de una capacidad militar autónoma por parte de Argentina y Brasil, como proponen Nogueira Batista (1992) y Helio Jaguaribe (1992), que no esté estrechamente coordinada con (léase supervisada por) los Estados Unidos, condenaría irremediablemente al fracaso el exitoso proceso de integración regional en marcha. Este objetivo de autonomía es impensable desde la óptica de lo que según Escudé y Fontana debería hacer la Argentina.

El punto ideológico central que opone a ambos países es que en Brasil las dirigencias están inspiradas por pensamientos realistas que asumen que la acumulación de poder estatal es el objetivo prioritario de los Estados; principios que están completamente contrapuestos a la ideología que inspira las políticas argentinas, que subordina el poder y la soberanía estatal al bienestar ciudadano, a la libertad y a la democracia ${ }^{28}$.

\section{La dimensión económica: Mercosur, Nafta-Alca y Alcsa.}

A nivel de la opinión pública y de la principal alianza de oposición (UCR-FREPASO), el Mercosur es y debe seguir siendo el principal objetivo de la política exterior argentina. El mismo pasa, necesariamente, 
por una alianza cada vez más estrecha con Brasil, para lo cual el Mercosur debería retomar una senda de "integración estratégica"29.

Para analistas como Atilio Borón, Brasil se ha opuesto con más vehemencia a la aspiración norteamericana de disciplinar económicamente a la región a través de ALCA. Desde esta perspectiva, Brasil busca fortalecer al Mercosur.

No obstante, hay matices en esta coincidencia de fondo. Desde perspectivas distintas Argentina y Brasil han hecho su apuesta al Mercosur: Brasil, viendo en éste un instrumento para su disputa con Estados Unidos y Argentina para fortalecer su comercio exterior y reducir la predominancia hegemónica subregional del Brasil.

A nivel de los establishment diplomáticos, el brasileño está mucho más comprometido con Mercosur que el argentino.

Sin embargo, desde la lectura de la actual formulación de política exterior en Buenos Aires, existen posiciones encontradas, entre aquellas que ven al Mercosur como una apuesta importante y otra que pone de relevancia el papel que éste podría jugar en beneficio de una política de hegemonía brasileña sobre el Cono Sur.

Es interesante, en este sentido, revisar las opiniones de un especialista extranjero, Joseph Tulchin. En un reciente reportaje publicado en Buenos Aires, Tulchin dice: "la Argentina no acepta ser segundo en el Mercosur. Hay una tradición en sostener esa política. Si uno mira objetivamente al Mercosur, Brasil lo maneja y la Argentina no va a aprovechar los beneficios del Mercosur si no reconoce que no son países simétricos. ${ }^{30}$

Argentina y Brasil, desde la reunión de Belo Horizonte que consolidó las posiciones preliminares (Denver, 1995; Cartagena, 1996), han mantenido una posición conjunta frente a Estados Unidos sobre el camino a seguir para la constitución del ALCA.

${ }^{29}$ Sobre esta interpretación de una concepción "estratégica" de la integración, que el modelo Mercosur firmado por Collor y Menem abandonó, hemos hecho diversos análisis a los que remitimos; en especial, "El Mercosur y el Área de Libre Comercio de América Latina en el contexto de la Reglonalización y la Globalización", en FUNAG, Globalizaçâo na América Latina: Integraçâo Solidária, Brasília, Fundaçâo Alexandre de Gusmâo, 1997, pp. 99-138.

30 "La Argentina y Estados Unidos. ¿El fin de la desconfianza? Diălogo con Joseph Tulchin", Archivos del Presente, Buenos Aires, № 3, Año 1, p. 28. En este sentido son coincidentes las apreciaciones acerca de que estas asimetrías con Brasil, lejos de reducirse, aumentan, dadas las diferencias apreciables respecto de los incentivos a la modernización productiva y a las condiciones de inversión. Ver al respecto, por ejemplo, El Economista, Buenos Aires, 28 de agosto de 1998, p. 8. 
Si bien existe coincidencia entre Argentina y Brasil, en el sentido de que primero hay que construir los bloques (building blocks), por lo cual ALCA debería coexistir con el Mercosur, posición contraria a la de Estados Unidos, que propugna la negociación individual de cada país al área de libre comercio, a través del Nafta (one for all), la posición pública brasileña ha sido más evidente.

No obstante, entre los formuladores y decisores de Buenos Aires, predominaría hoy la idea que ALCA no es un tema clave y que no se podría negociar aranceles con Estados Unidos si antes no se negocian las "reglas del juego". Aún los más férreos defensores del alineamiento con Estados Unidos (por ejemplo, Carlos Escudé) dicen "no a la estrategia norteamericana de negociación bilateral".

En cuanto a ALCSA parece existir en Argentina una posición coincidente, en el sentido de considerar que esta propuesta ha sido una pretensión brasileña de hacer de América del Sur su propio ALCA. La crítica argentina a la propuesta formulada por Itamar Franco es tanto hacia la forma "unilateral" de declararla -lo que ponía en duda el valor de "socio estratégico" que Brasil le asignaría supuestamente a Argentina-, como sobre su objetivo, que pone en cuestionamiento el valor intrínseco del Mercosur (Bernal-Meza, 1997; $1998 ; 1998 a)$.

\section{Conclusiones}

Es paradójico el curso de la historia: durante los años 1945 a 1976, aunque con ciertos intervalos, la percepción argentina era que Brasil era el apoyo sudamericano a las políticas hegemónicas norteamericanas. Ahora se coincide en la apreciación sobre la política norteamericana, pero ha cambiado el actor de soporte subregional. Éste, según lo definen hoy en Brasil, es la Argentina.

Existe una coincidencia muy estrecha entre las concepciones sobre la seguridad global y regional de Estados Unidos y Argentina. A su vez, Argentina y Brasil tienen claras y abiertas discrepancias en el pensamiento estratégico, lo que produce en consecuencia una clara disputa entre Estados Unidos y Brasil sobre estos temas. 
Para los formuladores y tomadores de decisión de la política exterior argentina actual, Brasil tiene una visión del mundo equivocada, ya que la globalización ha dejado obsoleto el conflicto entre el Norte y el Sur. Brasil se opone a Estados Unidos porque tiene el complejo pretensioso de creerse una potencia mundial y de ser considerada como tal, algo que los decisores argentinos hoy no están dispuestos a otorgarle. Hay una asimetría de poder entre Estados Unidos de una parte y Argentina y Brasil por otra que Brasil no ve.

Por lo tanto, Brasil mantiene con Estados Unidos una disputa sin sentido, que dificulta una proyección política de la relación ArgentinaBrasil y del Mercosur.

El sustento político de esta pretensión está dado por los paradigmas y enfoques teóricos que fundamentan su política exterior y de seguridad (concepción estado-céntrica; realismo; enfoque geopolítico), que se contraponen a la visión argentina. Por lo tanto, la continuidad de las políticas exterior y de seguridad de la Argentina tienen en sụ socio Brasil un serio escollo para su desarrollo futuro, lo que podría llevar a importantes dificultades bilaterales.

Según el pensamiento más influyente sobre la política exterior argentina actual, en Brasil persisten delirios de grandeza sobre su futuro como potencia mundial, cuestión que pone en peligro las relaciones bilaterales. Para los analistas más influyentes en el proceso de toma de decisiones sobre política exterior de Buenos Aires, el presidente Cardoso ha hecho importantes esfuerzos por limitar las diferencias políticas con Argentina, pero no ha podido conducir a Brasil a una posición más cercana a Occidente y, por tanto a Argentina, porque las élites brasileñas y el establishment no están dispuestos a renunciar a la acumulación de poder estatal como objetivo básico del Estado. La explicación es porque gobiernan un país que es considerablemente menos democrático política y socialmente y porque es un país esencialmente más oligárquico.

La extensión de esta política a las relaciones con Argentina se resume en conducir a ésta a aceptar su visión sobre el orden mundial y sobre el papel hegemónico de Estados Unidos en el Cono Sur; percibiéndose esfuerzos brasileños por poner a Argentina políticamente bajo su égida. 
Debemos coincidir en que la aspiración brasileña a ser considerado una gran potencia es una fuente de conflictos tanto con Estados Unidos como con Argentina. Para Buenos Aires, actualmente, no puede considerarse la posibilidad de creación de una capacidad militar-estratégica bilateral argentino-brasileña sin la coordinación con Estados Unidos.

Mientras prevalezcan en Buenos Aires las actuales políticas, las tendencias en Argentina y Brasil serán divergentes.

Brasil es considerado una cuña conflictiva en las relaciones entre Argentina y Estados Unidos, pero en Buenos Aires se asegura que no se va a permitir que esto suceda, de la misma forma en que no se va a permitir que Estados Unidos sea una cuña en las relaciones entre Argentina y Brasil.

Para la Argentina del gobierno actual, Brasil apunta a mantener una hegemonía en el área geográfica subhemisférica. Ofrece transparencia en cuestiones de seguridad en esta misma área, pero sin que ello implique una pérdida real de autonomía vis-à-vis los Estados Unidos.

Se desprende de aquí una gran paradoja: a medida que se ha fortalecido el acercamiento económico y ha progresado el Mercosur, las respectivas políticas exteriores y de seguridad de ambos países se han ido diferenciando.

Podría considerarse, sin embargo, que, al cambiar Argentina sus percepciones sobre las relaciones con Estados Unidos y la seguridad (global y hemisférica), el actor menor (Argentina), que opta por el desarme nuclear, deja aislado al segundo actor de poder hemisférico (Brasil), que lo obligaría a cambiar sus perspectivas de conflicto con la potencia hegemónica.

Como el gobierno del presidente Menem termina en 1999, es posible que esta tendencia divergente se revierta, como consecuencia del cambio en la política exterior, en particular sobre el retorno de las concepciones estado-céntricas, la revisión del alineamiento con Estados Unidos y sobre sus concepciones globales, incluyendo una visión estratégica de la integración bilateral que hoy está ausente.

Desde una perspectiva más amplia, menos comprometida ideológicamente con los paradigmas que sustentan la actual política exterior argentina, se considera en Buenos Aires que Argentina y Brasil plantean sus relaciones con Estados Unidos de manera diferente, las que provienen de las diferentes posiciones que como países tienen, respectivamente, en la nueva estructura de poder mundial que emergió después del fin de la Guerra Fría. 
Las interpretaciones de los formuladores y decisores de política exterior argentina es que las diferencias responden a los distintos paradigmas y enfoques de sus respectivas políticas exteriores. En tanto, para otros analistas más objetivos -o, al menos, más independientes- las diferencias obedecen a cuestiones más complejas.

En este sentido, algunas interpretaciones señalan que, como consecuencia de la inestabilidad política y los conflictos económicos internos del Brasil de los años 80 y 90 , ese país sufrió una pérdida de posiciones frente al mundo. "Ante esta situación y con la llegada de Cardoso, algunos analistas sostienen que Brasil revisa su paradigma de desarrollo nacionalista y se reformula su proyección internacional global, para lo cual el diálogo con Estados Unidos se hace imprescindible, aunque el mismo se hace desde una perspectiva y una forma distinta a la de Argentina (Busso, 1997:82).

Si bien Escudé también considera que la alianza de Argentina con Brasil cumple funciones de límite a la alianza argentina con Estados Unidos, el Mercosur es motivo de lecturas distintas. Como hemos señalado en documentos recientes (Bernal-Meza,1998;1998a), desde Buenos Aires se ha recriminado a Brasil la toma de posiciones de manera unilateral, entre ellas la búsqueda de su candidatura al Consejo de Seguridad, haciendo la propuesta abierta de ALCSA sin consultar y violando acuerdos y compromisos comerciales con Argentina.

Sin embargo, todo el análisis sobre las diferencias entre las concepciones globales, de la política mundial y de la seguridad, existentes entre ambos países, parten del supuesto de que existe, en cada uno de ellos, una correlación entre el discurso de su política exterior y la formulación de su respectiva política externa y de comercio exterior. Es decir, se parte del supuesto que cada Estado, a través de su gobierno, está implementando políticas externas e internas, ajustadas a esa visión del mundo, lo que conduce a una coherencia entre concepciones y políticas.

Concluyendo, en el caso brasileño, surgen dudas acerca de si esto es realmente así. Tomando en cuenta la política interna (económica, social) y la política de comercio exterior que lleva adelante el presidente Cardoso, surge la duda acerca de si Brasil hace en política interna lo que se necesita para alcanzar los objetivos que se plantean en el discurso de política exterior y de seguridad. 
Revisando análisis recientes ${ }^{31}$, uno podría llegar a la conclusión de que con Brasil ocurre hoy lo que en los análisis sobre la política exterior mexicana se decía allá por los años 70: a una política interna más autonomista, una política exterior conservadora; a una política interna conservadora, una política exterior autonomista, activa y no alineada.

"Ver, por ejemplo, Amado Luiz Cervo. Dice este autor que bajo la presidencia de Cardoso el pensamiento brasileño sería conducido al más avanzado estadio de adaptación a las tendencias del orden internacional de los años noventa, abandonando los requisitos de desarrollo interno mantenidos por la política exterior desde los años 30; aplicando una apertura del mercado interno sin negociación, privatizaciones sin cuidar el reforzamiento de la economía nacional, un sistema financiero puesto al servicio de la estabilización monetaria, con lo cual el Brasil seguiría una senda de debilitamiento y fragilidad económico-financiera igual que otros países que han aplicado la receta norteamericana. Cfr. "Politica de comércio exterior e desenvolvimento: a experiência brasileira", en Revista Brasileira de Política Internacional, Brasília, Año 40, № 2, 1997, pp. 5•26. 
Bibliografía:

Dr: Raúl Bernal-Meza

Las Percepciones de la Actual

Política Exterior Argentina sobre

la Política Exterior del Brasil y las

Relaciones Estados Unidos - Brasil.

Bandeira, Moniz (1995),

Estado nacional e Política

Internacional na América Latina,

Saô Paulo, Editora Ensaio, $2^{a}$ ediçâo.

Bernal-Meza, Raúl (1989),

Cooperación y Conflicto en la política

exterior latinoamericana: Dos enfoques,

Mendoza, Universidad Nacional de Cuyo-

Fac. de Ciencias Políticas y Sociales/

CERIAL.

(1997), "El Mercosur y el Area de Libre

Comercio de América Latina en el contexto

de la Regionalización y la Globalización", en FUNAG, Globalizaçâo na América

Latina: Integraçâo Solidária, Brasília,

Fundaçâo Alexandre de Gusmâo, 1997, pp. 99-138.

(1998), "Argentina, Brasil, Chile y Estados Unidos, en el contexto de la politica exterior y el Mercosur", en ALZOLA, Nilsa y CVITANOVIC, Dinko (Comps.), La Argentina y el Mundo del Siglo XX, Bahía Blanca, Universidad Nacional del Sur, pp.51-77.

(1998a), "As relaçôes entre Argentina, Brasil, Chile e Estados Unidos: Política Exterior e Mercosul", Revista Brasileira de Política Internacional, Brasília, Año 41, $N^{a}$ 1, 1998, pp. 89-107.

Buchrucker, Cristián (1997), "Amenazas globales y regionales en el pensamiento político-militar argentino: ayer y hoy", Mendoza, Universidad de Congreso, Doc. de dif. restringida; Programa de Postgrado en Relaciones Internacionales.
Busso, Anabella, A ocho años del Alineamiento: un análisis de la politica exterior argentina hacia los Estados Unidos, Rosario, CERIR, Cuadernos de Política Exterior Argentina, $N^{a} 10$, diciembre de 1997.

Cervo, Amado Luiz (1997), "Politica de comércio exterior e desenvolvimento: a experiência brasileira", Revista Brasileira de Política Internacional, Brasília, Año $40, N^{\circ} 2$, pp. 5-26.

Colacrai de Trevisan, Miriam (1992), "Perspectivas teóricas en la bibliografía de política exterior argentina".

Russell, Roberto (1992), Enfoques teóricos y metodológicos para el estudio de la política exterior; op. cit.; pp. 19-51.

De la Balze, Felipe A.M. (1995), "Argentina y Brasil: Enfrentando el Siglo $X X I$ ", en F.A.M. de la BALZE (comp.), Argentina y Brasil. Enfrentando el Siglo XXI, Buenos Aires, CARI/ABRA, pp. 13-130.

Di Tella, Torcuato (1995), El sistema político brasileño: partidos políticos y corporaciones, Buenos Aires, Instituto del Servicio Exterior de la Nación, Serie Documentos de Trabajo $N^{\circ} 6$.

Domínguez, Jorge (Editor), (1998), Seguridad Internacional, Paz y Democracia en el Cono Sur; Santiago, FLACSO.

Diamint, Ruth (1998), "Agenda de Seguridad de Argentina", en Francisco ROJAS ARAVENA (editor), La seguridad internacional en los países del $A B C$, Santiago de Chile, FLACSO; versión preliminar.

Escude, Carlos (1992), Realismo Periférico. Fundamentos para la nueva política exterior argentina, Buenos Aires, Planeta. 
(1995), El Realismo de los Estados Débiles. La política exterior del primer Gobieno Menem frente a la teoria de las relaciones internacionales, Buenos Aires, Grupo Editor Latinoamericano.

Escude, Carlos y Fontana, Andrés (1995), Divergencias Estratégicas en el Cono Sur: Las politicas de Seguridad de la Argentina frente a las del Brasil y Chile, Buenos Aires, Universidad Torcuato Di Tella, Working Paper $\mathrm{N}^{\circ} 20$, julio.

(1998), "Las políticas de seguridad de Argentina: sus fundamentos y contexto regional", en DOMINGUEZ, Jorge (Editor), Seguridad Internacional, Paz y Democracia en el Cono Sur, Santiago, FLACSO, pp. 81-123.

(1998a), “Argentina's Security Policies", en DOMINGUEZ, Jorge (Editor), InternationaI Security and Democracy, Pittsburgh, University of Pittsburgh Press, pp. 51-80.

Gualco, Jorge N. (1972),

Cono Sur: la elección de un destino, Buenos Aires, Com. Fabril Editora.

Guglialmelli, Juan E. (1975), "Argentina-Brasil, enfrentamiento o alianza para la liberación", Revista Estrategia, Buenos Aires, $N^{\circ} 36$, sept.-octubre.

Jaguaribe, Helio (1992),

"A nova Ordem Mundial", Política Externa, Vol. 1, Nª 1, junio 1992.

Kennedy, Paul, Chase, Robert S., Hill, Emily B. (1996), "Los Estados pivot", Archivos del Presente (Foreign Affairs), Buenos Aires, Año 2, $\mathrm{N}^{\circ} 4$, Otoño Austral/ 96, pp. 91-80.

Nogueira Batista, Paulo (1992),

"Nova Ordem u Desordem Internacional?", Política Externa, Vol. 1, № 1, junio 1992.
Massot, Vicente Gonzalo (1995), "Del equilibrio de enemistades a la cooperación bilateral", en Felipe DE LA BALZE (comp.), Argentina y Brasil. Enfrentando el Siglo XXI, op. cit.; pp. 217-240.

Mota Sardenberg, Renato (1995), Inserçâo Estratégica do Brasil no Cenário Internacional, Saô Paulo, Instituto de Estudos Avançados da Universidade de Saô Paulo.

Rojas Aravena, Francisco (Editor), (1998), La seguridad internacional en los paises del $A B C$, Santiago, Flacso; Versión perliminar.

Russell, Roberto (1992), "Introducción", en R. Russell (editor), Enfoques teóricos y metodológicos para el esitudio de la política exterior, Buenos Aires, RIAL/GEL, Grupo Editor Latinoamericano, pp. 7-18.

(1992a) Editor, La Política Exterior argentina en el Nuevo Orden Mundial, Buenos Aires, FLACSO/

Grupo Editor Latinoamericano.

Sanz, Pablo (1976), El Espacio Argentino, Buenos Aires, Edit. Pleamar.

Tomassini, Luciano (1980), "Los estudios internacionales en América Latina: experiencias y desafios", en Francisco Orrego Vicuña (Editor), Los estudios internacionales en América Latina. Realizaciones y desafíos, Santiago, Editorial Universitaria; pp. 96-122.

Tulchin, Joseph (1990), La Argentina y Estados Unidos. Historia de una desconfianza, Buenos Aires, Editorial Planeta.

Van Klaveren, Alberto (1984), "El análisis de la politica exterior latinoamericana: perspectivas teóricas", en Heraldo Muñoz y Joseph Tulchin (Comp.), Entre la autonomía y la subordinación. Política Exterior de los países latinoamericanos, Buenos Aires, Grupo Editor Latinoamericano, Tomo 1; pp. 14-49. 